03

\title{
Влияние свойств жидкости на режимы двухфазного течения в широком прямоугольном микроканале
}

\author{
(C) Ф.В. Роньшин ${ }^{1,2}$, В.В. Чеверда ${ }^{1,2}$, Е.А. Чиннов ${ }^{1,2}$, О.А. Кабов ${ }^{1,3}$ \\ ${ }^{1}$ Институт теплофризики им. С.С. Кутателадзе СО РАН, Новосибирск, \\ Россия \\ ${ }^{2}$ Национальный исследовательский Новосибирский государственный \\ университет, Новосибирск, Россия \\ ${ }^{3}$ Национальный исследовательский Томский политехнический \\ университет, Томск, Россия \\ E-mail: f.ronshin@gmail.com \\ Поступило в Редакцию 19 мая 2017 г. \\ В микроканале высотой $150 \mu \mathrm{m}$ и шириной $20 \mathrm{~mm}$ выполнено экспери- \\ ментальное исследование двухфазного течения с использованием различных \\ жидкостей: очищенной воды фирмы Milli-Q, 50\% водно-спиртового раствора \\ и FC-72. До и после эксперимента контролировались высота микроканала, \\ смачиваемость его стенок, поверхностное натяжение жидкостей. С использова- \\ нием шлирен-метода выявлены основные характеристики двухфазного течения \\ в широких диапазонах значений расхода газа и жидкости. Обнаружено, что \\ механизм формирования режима зависит от свойств используемой жидкости. \\ Зарегистрирован режим течения, когда по микроканалу движутся капли, \\ являющиеся вертикальными жидкостными перемычками. Показано, что при \\ использовании FC-72 пленка жидкости на верхней стенке канала формируется \\ во всем диапазоне значений расхода газа и жидкости.
}

DOI: 10.21883/PJTF.2018.07.45887.16881

Одной из актуальных задач теплофизики в наши дни является проблема охлаждения микроэлектронного оборудования. Разрабатываются компоненты микроэлектроники, микроэлектромеханические системы (МЭМС, микросистемы, микромашины), представляющие собой трехмерные мини- и микрообъекты, в которых характерные размеры элементов составляют миллиметры или микрометры, где наблюдаются высокие тепловые потоки (до $1 \mathrm{~kW} / \mathrm{cm}^{2}$ ). Эффективным решением пред- 
ставляется уменьшение размеров жидкостного теплообменника, так как отношение площади поверхности теплообмена к объему увеличивается обратно пропорционально поперечному размеру. Использование микроканалов позволяет существенно уменьшить среднюю толщину пленки при двухфазных течениях, что ведет к глобальной интенсификации теплообмена при испарении. В связи с этим для широкого круга технических приложений важное значение имеет понимание гидродинамики в микроканалах, которые обеспечивают наиболее эффективные процессы тепло- и массопередачи. Обзор публикаций по двухфазному течению в микроканалах содержится в [1-4]. Анализ исследований показывает, что на структуру двухфазного потока в основном влияют следующие параметры: геометрия и размеры канала, параметры входного участка [5] и свойства жидкости, такие как вязкость и поверхностное натяжение. В работах [6,7] проведено исследование механизмов, оказывающих влияние на формирование двухфазного течения. Выделено два новых вида неустойчивости (фронтальная и боковая), которые отвечают за формирование режимов в микроканале. В работе [8] исследовано влияние контактного угла смачивания на структуру двухфазного потока в круглом канале диаметром $1.6 \mathrm{~mm}$. Показано, что при изменении смачиваемости существенно меняются границы между режимами. В работе [9] проведено исследование влияния обработки поверхности на структуру двухфазного потока. Более регулярные стурктуры появились в гладком канале. В снарядном режиме в канале с тщательно обработанной поверхностью вместо капель наблюдалась пленка жидкости.

На основе анализа опубликованной литературы можно заключить, что смачиваемость микроканалов оказывает существенное влияние на режимы двухфазного течения. Целью настоящей работы является экспериментальное исследование двухфазного потока в прямоугольном микроканале высотой $150 \mu \mathrm{m}$, шириной $20 \mathrm{~mm}$ со следующими жидкостями: очищенная вода (Milli-Q), 50\% водно-спиртовой раствор и FC-72.

Описание установки и конструкции микроканала представлено в работе [10]. Для регистрации пленок жидкости на нижней и верхней стенках канала и соответственно определения режима двухфазного течения используется модификация шлирен-метода, представленная в [10]. Высота микроканала измерена при помощи конфокального метода на установке confocalDT IFC2451 и составляет $151.4 \pm 6.2 \mu \mathrm{m}$. При помощи установки KRUSS DSA 100 проведены измерения поверхностного натяжения жидкостей, а также углов смачивания верхней и

Письма в ЖТФ, 2018, том 44, вып. 7 
Результаты измерения краевых углов смачивания

\begin{tabular}{c|c|c|c}
\hline Жидкость & Краевой угол & $\begin{array}{c}\text { Нержавеющая } \\
\text { сталь }\end{array}$ & Кварц \\
\hline Вода & Натекающий & $106 \pm 1^{\circ}$ & $108 \pm 2^{\circ}$ \\
& Оттекающий & $25 \pm 3^{\circ}$ & $68 \pm 3^{\circ}$ \\
$50 \%$ водно-спиртовой раствор & Натекающий & $58 \pm 2^{\circ}$ & $71 \pm 2^{\circ}$ \\
& Оттекающий & $15 \pm 4^{\circ}$ & $35 \pm 4^{\circ}$ \\
FC-72 & Натекающий & \multicolumn{2}{|c}{$12 \pm 2^{\circ}$} \\
& Оттекающий & \multicolumn{2}{|c}{$4 \pm 2^{\circ}$}
\end{tabular}

нижней стенок микроканала. Поверхностное натяжение воды и водноспиртового раствора измерялось методом висящей капли, краевые углы смачивания измерялись методом лежащей капли. Для используемой воды поверхностное натяжение составляет $72 \mathrm{mN} / \mathrm{m}$, для водноспиртового раствора $-26 \mathrm{mN} / \mathrm{m}$, а для FC-72 $-10 \mathrm{mN} / \mathrm{m}$ (указано производителем жидкости $\left.3 \mathrm{M}^{\mathrm{TM}}\right)$. Результаты измерения контактных углов приведены в таблице.

Исследованы основные режимы течения двухфазного потока и определены границы между ними. Зарегистрированы следующие режимы двухфазных течений: струйный, пузырьковый, раздельный, кольцевой и вспененный. Построены режимные карты двухфазного течения для каждой из исследуемых жидкостей. В качестве координат использованы приведенные скорости газа $U_{S G}$ и жидкости $U_{S L}$, определяемые как отношение объемного расхода к площади поперечного сечения канала:

$$
U_{S L}=\frac{Q_{L}}{b h}, \quad U_{S G}=\frac{Q_{C}}{b h},
$$

где $Q_{L}$ - массовый расход жидкости, который задается шприцевым насосом Cole-Parmer EW-74905-54, $Q_{G}$ - массовый расход газа, который задается регулятором расхода El-Flow фирмы Bronkhorst, $b$ - ширина микроканала, $h$ - высота микроканала.

Также построены режимные карты двухфазного течения для каждой из исследуемых жидкостей, где в качестве координат использованы безразмерные числа Вебера

$$
\mathrm{We}_{S L}=\frac{\rho_{L} d_{h} U_{S L}^{2}}{\sigma}, \quad \mathrm{We}_{S G}=\frac{\rho_{G} d_{h} U_{S G}^{2}}{\sigma},
$$

Письма в ЖТФ, 2018, том 44, вып. 7 
где $\rho_{L}-$ плотность жидкости, $\rho_{G}-$ плотность газа, $d_{h}-$ гидравлический диаметр микроканала, $\sigma$ - поверхностное натяжение жидкости, измеренное на установке KRUSS.

При малых приведенных скоростях жидкости наблюдается струйный режим, когда газ движется в центральной части микроканала, а основная часть жидкости перемещается по его периферии вдоль боковых стенок. C увеличением приведенной скорости жидкости она начинает занимать значительно бо́льшую часть микроканала, а по центру движется газовая струя. При использовании водно-спиртового раствора и воды пленка на верхней стенке микроканала на образуется. В случае жидкости FC-72 на верхней стенке микроканала всегда формируется пленка жидкости, а также наблюдается движение вертикальных жидкостных перемычек (между верхней и нижней стенками микроканала), оставляющих за собой характерные следы на пленке жидкости (рис. 1,a). Струйный режим является специфическим для плоских мини- и микроканалов.

При увеличении приведенной скорости жидкости начинают формироваться стабильные горизонтальные перемычки жидкости, происходит переход от струйного режима к пузырьковому. В этом режиме по каналу движется жидкость, содержащая много небольших пузырьков газа. Размер и количество пузырьков изменяются в зависимости от расхода жидкости и газа, но размеры пузырьков всегда остаются гораздо меньшими ширины канала. Как правило, такие пузырьки движутся вдоль одной из стенок микроканала, что может быть обусловлено неоднородностью входного участка. С увеличением приведенных скоростей жидкости и газа частота пузырьков увеличивается.

При малых приведенных скоростях жидкости и больших приведенных скоростях газа наблюдается раздельный режим, в котором основная часть жидкости движется по нижней стенке микроканала в виде пленки, увлекаемой потоком газа. Верхняя стенка микроканала остается осушенной. Газ занимает больше половины сечения микроканала. Раздельный режим характерен только для некруглых микроканалов, так как в круглых микроканалах пленка замыкается, образуя кольцевой режим. При раздельном режиме можно наблюдать характерные волны на пленке жидкости (рис. 1,b). При использовании жидкости FC-72 раздельный режим не наблюдается, поскольку пленка на верхней стенке канала формируется во всем диапазоне значений расхода жидкости и газа. 

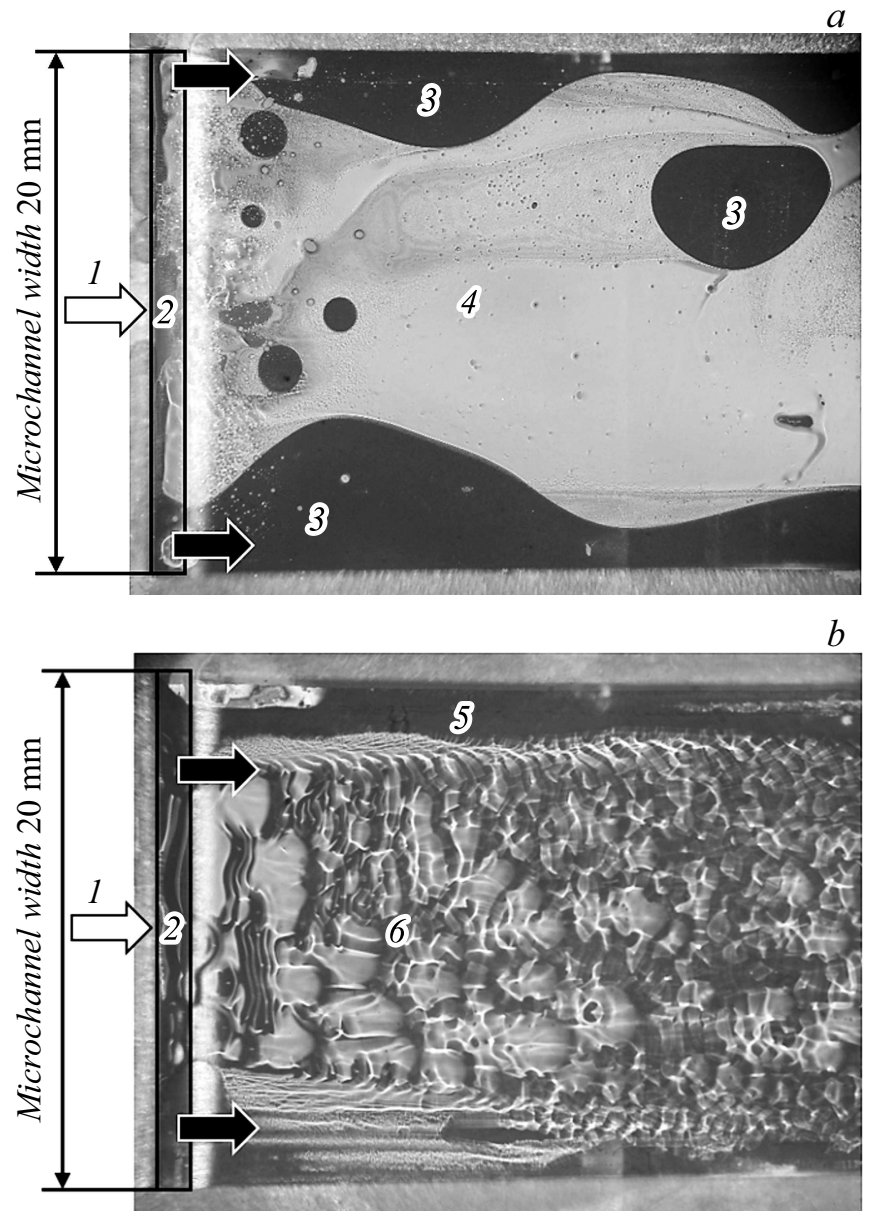

Рис. 1. Режимы двухфазного течения в микроканале сечением $0.15 \times 20 \mathrm{~mm}$. $a$ - струйный режим при $U_{S G}=0.556 \mathrm{~m} / \mathrm{s}, U_{S L}=0.011 \mathrm{~m} / \mathrm{s}$ с использованием FC-72; $b$ - раздельный режим при $U_{S G}=27.778 \mathrm{~m} / \mathrm{s}, U_{S L}=0.027 \mathrm{~m} / \mathrm{s}$ с использованием водно-спиртового раствора. 1 - вход газа в микроканал, 2 вход жидкости в микроканал, 3 - жидкость, 4 - пленка на верхней стенке микроканала, 5 - осушенная область в микроканале, 6 - пленка жидкости на нижней стенке микроканала. Светлая стрелка - направление движения газа, темные стрелки - направления движения жидкости.

Письма в ЖТФ, 2018, том 44, вып. 7 

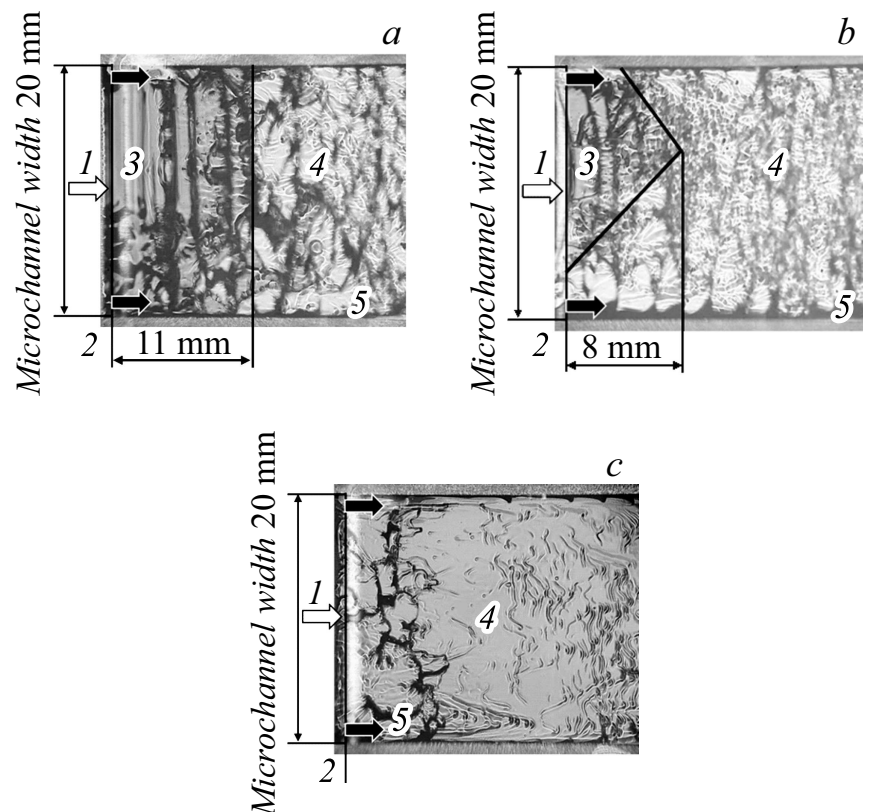

Рис. 2. Шлирен-фотографии кольцевого режима, где в качестве жидкости используются вода $(a)$, водно-спиртовой раствор $(b)$ и FC-72 $(c) .1$ - вход газа в микроканал, 2 - вход жидкости в микроканал, 3 - пленка на нижней стенке микроканала, 4 - пленка на верхней стенке микроканала, 5 - жидкость. Светлая стрелка - направление движения газа, темные стрелки - направления движения жидкости.

При увеличении приведенной скорости жидкости пленка образуется на верхней стенке микроканала, происходит переход к кольцевому режиму. При использовании в качестве жидкости воды пленка на верхней стенке микроканала формируется равноудаленно на расстоянии $11 \mathrm{~mm}$ от сопла жидкости (рис. 2,a). В случае водно-спиртового раствора формирование пленки жидкости на верхней стенке микроканала происходит сначала у боковых стенок микроканала, а затем в его центральной части, причем на расстоянии, меньшем, чем в случае использования в качестве рабочей жидкости воды (рис. 2,b). При использовании в качестве жидкости FC-72 пленка на верхней стенке 


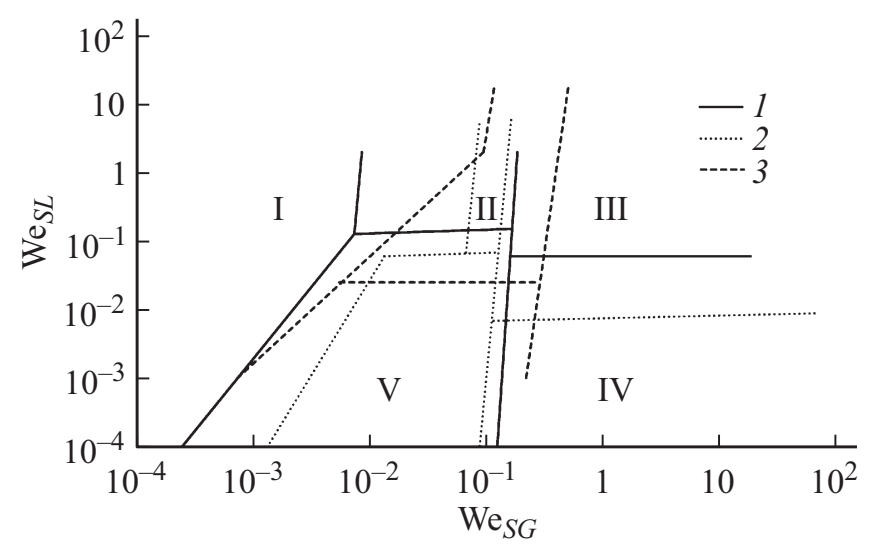

Рис. 3. Сравнительная режимная карта для микроканала сечением $0.15 \times 20 \mathrm{~mm}$ при использовании воды (1), 50\% водно-спиртового раствора (2) и FC-72 (3). Режимы течений: I - пузырьковый, II - вспененный, III кольцевой, IV - раздельный, V - струйный.

микроканала формируется непосредственно возле сопла жидкости за счет набросов жидкости на верхнюю стенку микроканала (рис. 2,c). В этом случае пленка на верхней стенке микроканала формируется вследствие фронтальной неустойчивости. Таким образом, в зависимости от свойств жидкости за формирование пленки жидкости на верхней стенке микроканала отвечают различные механизмы.

При приведенных скоростях жидкости от 0.1 до $1 \mathrm{~m} / \mathrm{s}$ и приведенных скоростях газа от 1 до $10 \mathrm{~m} / \mathrm{s}$ наблюдается вспененный режим. Для данного режима характерны особенности как струйного, так и пузырькового режима. Характерной его особенностью является наличие сплошных и разорванных горизонтальных жидкостных перемычек между боковыми частями канала. Со временем такие перемычки могут как разрушаться, так и формироваться. Этот режим характерен для вертикальных каналов, а также наблюдается в широких горизонтальных микроканалах. Данный режим подробно рассмотрен в работе [7].

На рис. 3 представлено сравнение режимных карт, где в качестве координат используются числа Вебера. Видно, что при использовании FC-72 вспененный режим образуется при наименьших значениях $\mathrm{We}_{S L}$.

Письма в ЖТФ, 2018, том 44, вып. 7 
При использовании водно-спиртового раствора и FC-72 переход от струйного к раздельному режиму (или к кольцевому для FC-72) наблюдается при меньших значениях $\mathrm{We}_{S G}$, чем в случае использования воды. Происходит это потому, что водно-спиртовой раствор и FC-72 лучше смачивают поверхность, а значит, пленка жидкости образуется при меньших значениях расхода газа. Этим же можно объяснить сдвиг границы между раздельным и кольцевым режимами в сторону меньших значений $\mathrm{We}_{S L}$ при переходе от воды к водно-спиртовому раствору. При использовании FC-72 раздельный режим не зарегистрирован, пленка на верхней стенке канала образовывалась во всем диапазоне значений расхода газа и жидкости.

В заключение следует отметить, что для каналов с прямоугольным сечением и высотой $150 \mu \mathrm{m}$ были обнаружены особенности режимов двухфазного течения, которые не наблюдались в предыдущих исследованиях. Установлены основные различия двухфазных течений в зависимости от свойств жидкости. Обнаружено, что в зависимости от используемой жидкости меняется механизм формирования режима двухфазного течения. Показано, как меняются границы между режимами в зависимости от используемой жидкости. В частности, обнаружено, что при использовании FC-72 пленка на верхней стенке канала образуется во всем диапазоне значений расхода газа и жидкости, из-за чего раздельный режим не формируется.

Исследование выполнено при финансовой поддержке РФФИ (№ 1638-00713 мол_а).

\section{Список литературы}

[1] Чиннов E.A., Кабов О.А. // Теплофизика высоких температур. 2006. Т. 44. № 5. C. 777-795.

[2] Shao N., Gavriilidis A., Angeli P. // Chem. Eng. Sci. 2009. V. 64. P. 2749-2761.

[3] Ребров Е.В. // Теорет. основы хим. технологии. 2010. Т. 44. № 4. С. 371-383.

[4] Чиннов Е.A., Роньшин Ф.В., Кабов О.A. // Теплофизика и аэромеханика. 2015. T. 22. № 3. C. 265-284.

[5] Минаков А.В., Шебелева А.А., Ягодницына А.А., Ковалев А.В., Бильский А.В. // Письма в ЖТФ. 2017. Т. 43. В. 18. С 82-89.

[6] Chinnov E.A., Ron'shin F.V., Kabov O.A. // Interfacial Phenomena Heat Transfer. 2015. V. 3. N 3. P. 243-257.

Письма в ЖТФ, 2018, том 44, вып. 7 
[7] Chinnov E.A., Ron'shin F.V., Kabov O.A. // Int. J. Multiphase Flow. 2016. V. 80. P. 57-68.

[8] Barajas A.M., Panton R.L. // Int. J. Multiphase Flow. 1993. V. 19. N 2. P. $337-$ 346.

[9] Serizawa A., Feng Z., Kawara Z. // Exp. Thermal Fluid Sci. 2002. V. 26. P. $703-$ 714.

[10] Ronshin F.V., Cheverda V.V., Chinnov E.A., Kabov O.A. // Interfacial Phenomena Heat Transfer. 2016. V. 4. N 2-3. P. 191-205.

Письма в ЖТФ, 2018, том 44, вып. 7 